\title{
Impact of COVID-19 Pandemic on Neurosurgical Practice in a Tertiary Care Center in India
}

\author{
Rahul Singh ${ }^{1}$ Anurag Sahu ${ }^{1} \quad$ Kulwant Singh ${ }^{1} \quad$ Ravi Shankar Prasad ${ }^{1} \quad$ Nityanand Pandey ${ }^{1}$ \\ Ramit Chandra Singh ${ }^{1}$
}

${ }^{1}$ Department of Neurosurgery, Institute of Medical Sciences, Banaras Hindu University, Varanasi, India

Address for correspondence Anurag Sahu, MCh, Department of Neurosurgery, Institute of Medical Sciences, Banaras Hindu University, Varanasi 221005, India (e-mail: anuragsahubhuneurosurgery@gmail.com).

J Neurosci Rural Pract:2021;12:24-32

\begin{abstract}
Keywords

- COVID-19

- neurosurgical practice

- pandemic

- virtual learning

- neurosurgical

emergency

- neurosurgical training
\end{abstract}

Objectives The aim of the study is to determine the magnitude of repercussions of coronavirus disease 2019 (COVID-19) pandemic on neurosurgical specialty and formulate a management approach.

Materials and Methods This combined retrospective and prospective study was done in neurosurgical specialty of IMS-BHU, Varanasi, India, a tertiary care center, between January 1, 2020 and May 31, 2020. Analysis of impact on neurosurgical emergency and electives was done over before pandemic, during lockdown 1 and 2 and during lockdown 3 and 4 timelines. Effects of COVID-19 pandemic on psychology of neurosurgical team (50 members) and on patient party (88) were also evaluated. Virtual learning and webinars as a substitute to residential neurosurgical training were analyzed by a questionnaire given to 13 neurosurgeons of our department.

Statistical Analysis Ordinary one-way ANOVA (analysis of variance) and unpaired $t$-test were used according to data analyzed. $p<0.05$ was considered statistically significant. GraphPad Prism software was used for this analysis.

Results On an average 8.22 admissions per day were done in neurosurgical emergency before pandemic. After lockdown these figures reduced to 3.2 admissions per day during lockdown 1 and 2 and to 5.36 admissions per day during lockdown 3 and 4 . There was significant reduction in neurotrauma admission rate during lockdown $(p<0.0001)$ at our center. There was $76 \%$ reduction in emergency neurosurgical operated cases during pandemic. There was significant reduction in outpatient department (OPD) attendance per day, OPD admissions per day $(p<0.0001)$, and total elective surgeries $(p<0.0001)$ during lockdown. Of 50 neurosurgical team members (neurosurgeons, nursing, and ground staff) interviewed, $90 \%$ of them had the fear of contacting the COVID-19 disease, fear of well-being of family and children, and difficulty in transport. Three out of 13 neurosurgeons $(23.1 \%)$ agreed on change in practice based on what they learned from virtual teaching and webinars and only two of them (15.4\%) accepted improvement of skills based on virtual learning.

Conclusion The COVID-19 pandemic is causing a significant impact on health care systems worldwide. For conserving resources elective surgical procedures should be limited. This pandemic has a negative impact on neurosurgical resident training program and psychology of both neurosurgical unit and patients.
DOI https://doi.org/ $10.1055 / \mathrm{s}-0040-1716455$ ISSN 0976-3147. (c) 2020. Association for Helping Neurosurgical Sick People.

This is an open access article published by Thieme under the terms of the Creative Commons Attribution-NonDerivative-NonCommercial-License, permitting copying and reproduction so long as the original work is given appropriate credit. Contents may not be used for commercial purposes, or adapted, remixed, transformed or built upon. (https://creativecommons.org/licenses/by-nc-nd/4.0/) Thieme Medical and Scientific Publishers Pvt. Ltd., A-12, 2nd Floor, Sector 2, Noida-201301 UP, India 


\section{Introduction}

The coronavirus disease 2019 (COVID-19) pandemic caused due to 2019 novel coronavirus (severe acute respiratory syndrome coronavirus 2) has threatened the human civilization ${ }^{1}$. Coronavirus infection was first identified in India on January 30, 2020, linked to China. ${ }^{2}$ The number of cases and transmission increased during subsequent months mostly linked with a travel history to affected countries and close contacts of infected individuals. On March 12, 2020, it was declared as a global pandemic by WHO (World Health Organization). On March 24, 2020, the Prime Minister of India declared a nationwide lockdown for 21 days, affecting 1.3 billion people of India. ${ }^{2,3}$ In India, till now lockdown has been implicated in four phases, viz., lockdown 1 (March 25, 2020 to April 14, 2020), lockdown 2 (April 15, 2020 to May 3, 2020), lockdown 3 (May 4, 2020 to May 17, 2020), and lockdown 4 (May 18, 2020 to May 31, 2020). During these lockdown periods, all the outpatient departments (OPDs) and elective surgeries were temporarily suspended in government hospitals. This lockdown and COVID-19 pandemic has imposed a striking repercussion on the neurosurgery specialty. Management protocol for patient care coming to neurosurgical emergency is very critical for the safety of both the health care workers (HCWs) (including neurosurgeons, nurses, and hospital sanitary staff) and the patient party. This study aims at determining the magnitude of repercussion of COVID-19 pandemic on neurosurgical specialty and formulate a management approach for better management and safety of neurosurgeons and other health care staff keeping in mind the constraints and limitations in a government hospital of a developing country.

\section{Material and Methods}

This combined retrospective and prospective study was done in neurosurgical specialty of IMS-BHU, Varanasi, India, a tertiary care center, between January 1, 2020 and May 31, 2020. Retrospective data were collected from medical and surgical records before lockdown (i.e., from January 1, 2020 to March $24,2020)$. Thereafter, data were collected prospectively from March 25, 2020 till May 31, 2020 during lockdown 1 to 4.

Four timelines were considered for evaluating the repercussion of COVID-19 pandemic on neurosurgical specialty. These were: (1) before pandemic (January 1, 2020 to February 29, 2020), (2) during pandemic before lockdown (March 1, 2020 to March 24, 2020), (3) Lockdown 1 and 2 (March 25, 2020 to May 3, 2020) with total lockdown, and (4) Lockdown 3 and 4 (May 4, 2020 to May 31, 2020) with relaxations. Analysis of impact on neurosurgical emergency was done considering admissions, mode of injury, total number of surgeries, number of cranial surgeries, number of spinal surgeries, number of conservatively managed cases, and mortality over these four timelines.

For impact on elective neurosurgical cases, OPD attendance/Telemedicine OPD attendance, OPD admissions/ Telemedicine OPD admissions, total number of elective surgeries, number of elective cranial surgeries, and number of elective spinal surgeries, mortality and discharges were analyzed before COVID-19 pandemic, before lockdown and during lockdown timeline.

Psychological and physical impacts on $50 \mathrm{HCWs}$ (including neurosurgeons, nursing, and ground staff) based on common interview format were also analyzed. We also tried to determine the repercussion of COVID-19 pandemic on neurosurgical patients and their relatives by interviewing 88 patients and relatives attending our trauma center casualty. Consent was taken from all and their identities were not revealed.

Effect of COVID-19 pandemic on residency training was also evaluated. Virtual classes and webinars as an alternative to actual neurosurgical resident training were assessed. For this seven senior residents and six consultants of our department were given questionnaires regarding participation in neurosurgical virtual learning activities, paying fees to participate in webinars, increase/decrease in participation in neurosurgical virtual learning activities, participation in international/national organized virtual learning activity, change in practice based on what they learned from these activities, improvement of skills based on virtual learning, increased communication with professional colleagues, opportunities provided, future participation in virtual learning, and alteration in neurosurgical training and education strategies.

All patients coming to the casualty were triaged for suspected COVID-19 infection as per our institutional protocol (-Fig. 1). As report of COVID-19 testing is available in 24 to 48 hours at our center so to safeguard the patient and the HCWs including neurosurgeons, we used an algorithmic approach to handle such cases ( - Fig. 1). Detailed account of management approach is dealt with in discussion.

Statistical tests were done using GraphPad Prism version 8.3.0 software. The data were summarized using medians/mean and counts and percentages for continuous and categorical variables, respectively. Ordinary one-way ANOVA (analysis of variance) and unpaired $t$-test were used according to data analyzed. $p<0.05$ was considered statistically significant.

\section{Results}

Total number of patients admitted in neurotrauma within 2 months before the pandemic in January and February were 493. On an average, 8.22 patients were admitted during this time period. However, during pandemic before the lockdown was enacted in India, i.e., between March 1, 2010 and March 25, 2020, a total of 202 patients with admission rate of 8.42 patients per day was evident. After lockdown these figures reduced to 128 admissions (3.2/d) during lockdown 1 and 2 and to 150 admissions (5.36/d) during lockdown 3 and 4 (-Table 1). There was significant reduction in neurotrauma admission rate during lockdown $(p<0.0001)$ at our center ( - Table $\mathbf{1})$.

There appears to be an increase in physical assault as mode of injury when compared with earlier values. However, no significant difference between modes of injury was found ( $p=0.8318$ ) on comparing the four 


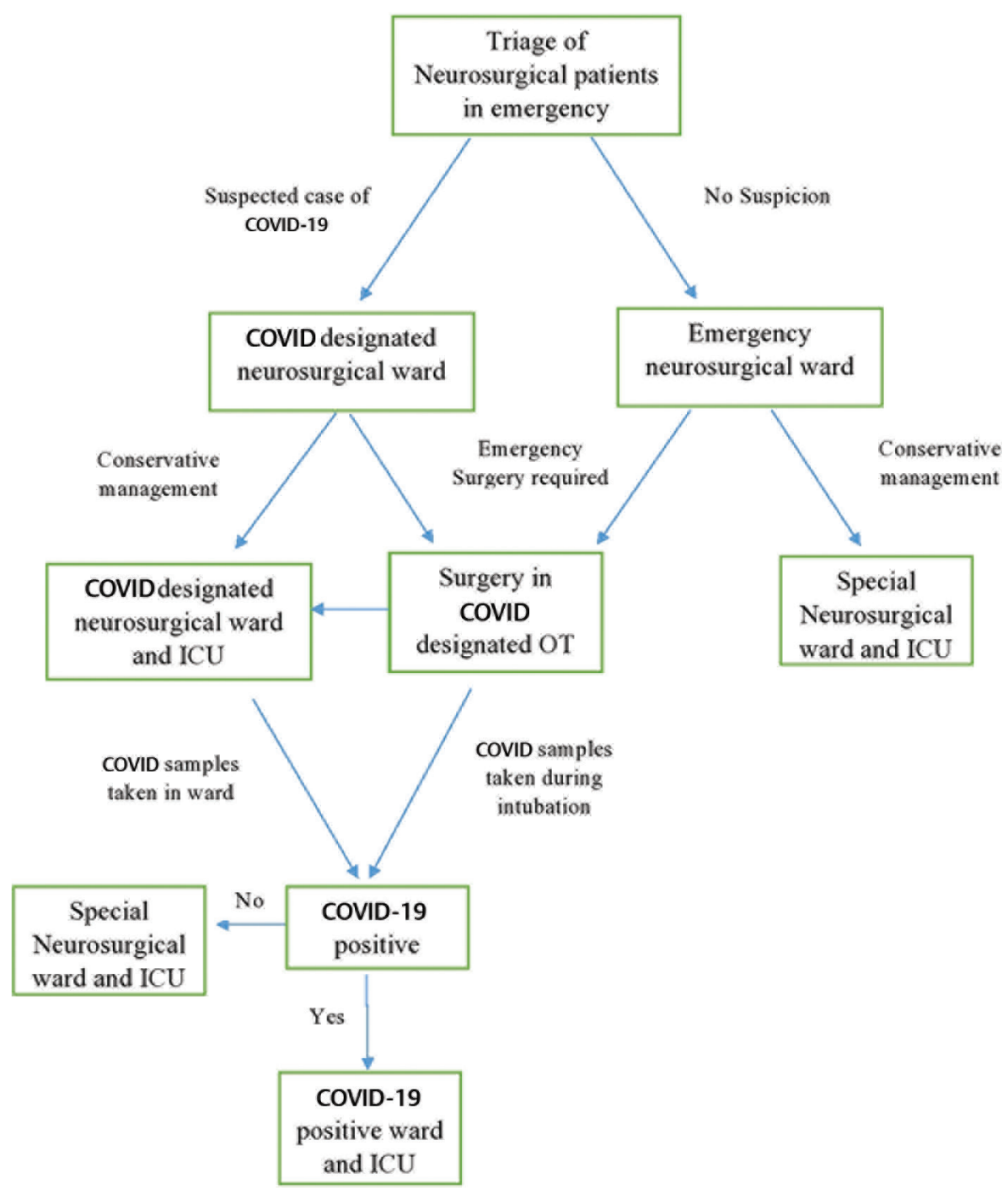

Fig. 1 Management algorithm of neurosurgical emergency patient in COVID-19 pandemic. (COVID designated wards are wards where COVID-19 suspected patients are quarantined and treated). COVID-19, coronavirus disease 2019.

timelines (-Table 1$)$. There was significant decrease in cranial injury $(p<0.0001)$ and spinal injury $(p<0.0001)$ admissions in neurotrauma at our center. Number of surgeries performed in emergency also suffered significant reduction $(p<0.0001)$ during lockdown ( - Table $\mathbf{1})$. Number of conservatively managed patients $(p<0.0001)$ and mortality $(p<0.0001)$ also were significantly reduced, respectively ( - Table $\mathbf{1})$.

During COVID-19 pandemic, 0.8 cases per day and before pandemic 1.56 cases per day were the average rates of surgery. There was $76 \%$ reduction in emergency neurosurgical cases during pandemic.

Neurosurgery OPD attendance per day was on an average of 166 patients during January and February (before pandemic), 133 patients during pandemic but before lockdown and 15 patients in Telemedicine OPD, respectively. During lockdown OPD, elective admissions and surgeries were suspended and Telemedicine OPD was started and semiemergent/ emergency cases were admitted via telemedicine OPD and operated (-Table 2). There was a significant reduction in OPD attendance per day $(p<0.0001)$, OPD admissions per day $(p<0.0001)$, total elective surgeries $(p<0.0001)$, cranial and spinal surgeries (each $p<0.0001$ ) and elective mortality $(p<0.0001)$, and discharges $(p<0.0001)$ during these three timelines ( - Table 2).

Of all cases operated on emergency basis, EDH (33.7\%), contusions (23.9\%), and acute SDH (14.1\%) constituted the majority of cases before pandemic. Similarly, EDH (27\%), contusions (23\%), and acute SDH (17.6\%) were the most common emergency cases operated during pandemic (-Table 3 ). No significant difference was found between the patterns of diagnosis of operated patients ( $p=0.8943$ ).

Of 50 neurosurgical team members (neurosurgeons, nursing and ground staff) interviewed, $90 \%$ of them had fear of 
Table 1 Neurotrauma before and during COVID-19 pandemic

\begin{tabular}{|c|c|c|c|c|c|c|}
\hline $\begin{array}{l}\text { S. } \\
\text { no }\end{array}$ & Characteristics & $\begin{array}{l}\text { Before } \\
\text { pandemic } \\
\text { (January to } \\
\text { February) } \\
\text { (60 d) }\end{array}$ & $\begin{array}{l}\text { During } \\
\text { pandemic } \\
\text { (before } \\
\text { lockdown) } \\
\text { (24 d) }\end{array}$ & $\begin{array}{l}\text { During } \\
\text { pandemic } \\
\text { (lockdown } 1 \\
\text { and } 2 \text { ) } \\
\text { (40 d) }\end{array}$ & $\begin{array}{l}\text { During } \\
\text { pandemic } \\
\text { (lockdown } 3 \\
\text { and } 4 \text { ) } \\
\text { (28 d) }\end{array}$ & $p$-Value \\
\hline 1. & $\begin{array}{l}\text { Total number of } \\
\text { neurotrauma cases } \\
\text { admitted (cases/d) }\end{array}$ & $\begin{array}{l}493 \\
(\text { mean }=8.22, \\
S D=1.25)\end{array}$ & $\begin{array}{l}202 \\
(\text { mean }=8.42, \\
S D=1.1)\end{array}$ & $\begin{array}{l}128 \\
(\text { mean }=3.2, \\
S D=0.8)\end{array}$ & $\begin{array}{l}150 \\
(\text { mean }=5.36, \\
S D=1.4)\end{array}$ & $\begin{array}{l}P 1=0.4956 \\
P 2<0.0001^{\mathrm{a}} \\
P 3<0.0001^{\mathrm{a}} \\
P_{\text {Overall }}<0.0001^{\mathrm{a}}\end{array}$ \\
\hline \multirow[t]{5}{*}{2.} & Mode of injury & & & & & \\
\hline & Road traffic accident & $\begin{array}{l}392 \\
(\text { mean }=6.53, \\
S D=1.25)\end{array}$ & $\begin{array}{l}166 \\
(\text { mean }=6.92, \\
S D=1.40)\end{array}$ & $\begin{array}{l}42 \\
(\text { mean } 1.05, \\
S D=0.4)\end{array}$ & $\begin{array}{l}79 \\
(\text { mean }=2.82, \\
S D=0.70)\end{array}$ & $P 1=0.9826$ \\
\hline & Physical assault & $\begin{array}{l}50 \\
(\text { mean }=0.83, \\
S D=0.20)\end{array}$ & $\begin{array}{l}21 \\
(\text { mean }=0.87, \\
S D=0.2)\end{array}$ & $\begin{array}{l}65 \\
(\text { mean }=1.62, \\
S D=0.23)\end{array}$ & $\begin{array}{l}50 \\
(\text { mean }=1.79, \\
S D=0.5)\end{array}$ & $P 2=0.4465$ \\
\hline & Fall from height & $\begin{array}{l}43 \\
(\text { mean }=0.72, \\
S D=0.3)\end{array}$ & $\begin{array}{l}13 \\
(\text { mean }=0.54, \\
S D=0.25)\end{array}$ & $\begin{array}{l}20 \\
(\text { mean }=0.5 \\
S D=0.02)\end{array}$ & $\begin{array}{l}21 \\
(\text { mean }=0.75, \\
S D=0.20)\end{array}$ & $P 3=0.6757$ \\
\hline & Spontaneous fall & $\begin{array}{l}8 \\
(\text { mean }=0.13, \\
S D=0.01)\end{array}$ & $\begin{array}{l}2 \\
(\text { mean }=0.08, \\
S D=0.001)\end{array}$ & $\begin{array}{l}1 \\
(\text { mean }=0.025, \\
S D=0.002)\end{array}$ & 0 & $P_{\text {overall }}=0.8318$ \\
\hline 3. & Cranial injuries & $\begin{array}{l}461 \\
(\text { mean }=7.68, \\
S D=1.2)\end{array}$ & $\begin{array}{l}184 \\
(\text { mean }=7.67, \\
S D=1.1)\end{array}$ & $\begin{array}{l}121 \\
(\text { mean }=3.02, \\
S D=0.8)\end{array}$ & $\begin{array}{l}133 \\
(\text { mean }=4.75, \\
S D=0.6)\end{array}$ & $\begin{array}{l}P 1=0.9716 \\
P 2<0.0001^{\mathrm{a}} \\
P 3<0.0001^{\mathrm{a}} \\
P_{\text {overall }}<0.0001^{\mathrm{a}}\end{array}$ \\
\hline 4. & Spinal injuries & $\begin{array}{l}32 \\
(\text { mean }=0.53, \\
S D=0.1)\end{array}$ & $\begin{array}{l}18 \\
(\text { mean }=0.75, \\
S D=0.1)\end{array}$ & $\begin{array}{l}7 \\
(\text { mean }=0.17, \\
S D=0.01)\end{array}$ & $\begin{array}{l}17 \\
(\text { mean }=0.61, \\
S D=0.05)\end{array}$ & $\begin{array}{l}P 1<0.0001^{\mathrm{a}} \\
P 2<0.0001^{\mathrm{a}} \\
P 3=0.0001^{\mathrm{a}} \\
P_{\text {overall }}<0.0001^{\mathrm{a}}\end{array}$ \\
\hline 5. & Number of surgeries & $\begin{array}{l}92 \\
(\text { mean }=1.53, \\
S D=0.6)\end{array}$ & $\begin{array}{l}41 \\
(\text { mean }=1.71, \\
S D=0.8)\end{array}$ & $\begin{array}{l}11 \\
(\text { mean }=0.27, \\
S D=0.03)\end{array}$ & $\begin{array}{l}22 \\
(\text { mean }=0.79, \\
S D=0.01)\end{array}$ & $\begin{array}{l}P 1=0.2637 \\
P 2<0.0001^{\mathrm{a}} \\
P 3<0.0001^{\mathrm{a}} \\
P_{\text {overall }}<0.0001^{\mathrm{a}}\end{array}$ \\
\hline 6. & $\begin{array}{l}\text { Conservatively managed } \\
\text { cases }\end{array}$ & $\begin{array}{l}401 \\
(\text { mean }=6.68, \\
S D=1.1)\end{array}$ & $\begin{array}{l}161 \\
(\text { mean }=6.71, \\
S D=1.3)\end{array}$ & $\begin{array}{l}115 \\
(\text { mean }=2.87, \\
S D=0.7)\end{array}$ & $\begin{array}{l}126 \\
(\text { mean }=4.5 \\
S D=0.5)\end{array}$ & $\begin{array}{l}P_{1}=0.9150 \\
P 2<0.0001^{\mathrm{a}} \\
P 3<0.0001^{\mathrm{a}} \\
P_{\text {overall }}<0.0001^{\mathrm{a}}\end{array}$ \\
\hline 7. & Mortality & $\begin{array}{l}35 \\
(\text { mean }=0.58 \\
S D=0.1)\end{array}$ & $\begin{array}{l}12 \\
(\text { mean }=0.5 \\
S D=0.12)\end{array}$ & $\begin{array}{l}8 \\
(\text { mean }=0.2 \\
S D=0.02)\end{array}$ & $\begin{array}{l}16 \\
(\text { mean }=0.57, \\
S D=0.08)\end{array}$ & $\begin{array}{l}P 1=0.0025^{\mathrm{a}} \\
P 2<0.0001^{\mathrm{a}} \\
P 3=0.6439 \\
P_{\text {overall }}<0.0001^{\mathrm{a}}\end{array}$ \\
\hline
\end{tabular}

Abbreviations: COVID-19, coronavirus disease 2019; SD, standard deviation.

aStatistically significant $(p<0.05)$.

Note: $P 1$ = between columns 3 and $4, P 2$ = between columns 3 and $5, P 3=$ between columns 3 and 6 , and $P_{\text {overall }}=$ between columns 3 to 6 .

contacting the COVID-19 disease, fear of well-being of family and children, and difficulty in transport. Other common psychological impacts of COVID-19 on them were lack of satisfaction with protective gears provided (78\%), suffocating feeling in PPE kit (40\%), breathing difficulty while using N95 mask (30\%), anxiety (24\%), and depression (10\%) (-Table 4 ). Of 88 patients and attendants interviewed, all of them (100\%) were having fear and anxiety of contacting the COVID-19 disease and were having difficulty in getting food and necessary transportation for patient. Most of them were having difficulty in getting shelters near hospital (81.8\%) and were having difficulty in follow-up after discharge (71.6\%) (-Table 4).
Impact of virtual learning and webinars on neurosurgical training was assessed on 13 neurosurgeons (residents + consultants) and most of them (84.6\%) were willing to participate in such activities and had perhaps increased their participation in such activities in this pandemic era. They agreed on future participation in such activities (84.6\%) and admitted that virtual learning and webinars increase communication with professional colleagues ( - Table 5). Only three neurosurgeons $(23.1 \%$ ) agreed on change in practice based on what they learned from these activities and only two of them (15.4\%) accepted improvement of skills based on virtual learning (-Table 5). 
Table 2 Neurosurgical electives before and during COVID-19 pandemic

\begin{tabular}{|c|c|c|c|c|c|}
\hline S. no & Characteristics & $\begin{array}{l}\text { Before } \\
\text { pandemic } \\
\text { (January to } \\
\text { February) (60) }\end{array}$ & $\begin{array}{l}\text { During pandemic } \\
\text { before lockdown (24) }\end{array}$ & $\begin{array}{l}\text { During pandemic } \\
\text { (lockdown } 1 \text { to } 4 \text { ) } \\
\text { telemedicine OPD } \\
(68)\end{array}$ & $p$-Value \\
\hline 1. & $\begin{array}{l}\text { OPD attendance } / \mathrm{d} \\
\text { (SD) }\end{array}$ & $\begin{array}{l}166 \\
(S D=10.4)\end{array}$ & $\begin{array}{l}133 \\
(S D=12.4)\end{array}$ & $\begin{array}{l}15 \\
(S D=1.4)\end{array}$ & $<0.0001^{\mathrm{a}}$ \\
\hline 2. & OPD admission/d & $\begin{array}{l}\text { mean }=5 \\
S D=1.1\end{array}$ & $\begin{array}{l}\text { mean }=3 \\
S D=0.8\end{array}$ & $\begin{array}{l}\text { mean }=1.5 \\
\mathrm{SD}=0.08\end{array}$ & $<0.0001^{\mathrm{a}}$ \\
\hline 3. & Total surgeries & $\begin{array}{l}122 \\
(\text { mean }=2.03 \\
S D=0.3)\end{array}$ & $\begin{array}{l}33 \\
(\text { mean }=1.37, S D=0.7)\end{array}$ & $\begin{array}{l}10 \\
(\text { mean }=0.15, S D=0.03)\end{array}$ & $<0.0001^{\mathrm{a}}$ \\
\hline 4. & Cranial cases & $\begin{array}{l}83 \\
(\text { mean }=1.4 \\
S D=0.3)\end{array}$ & $\begin{array}{l}16 \\
(\text { mean }=0.66, S D=0.09)\end{array}$ & $\begin{array}{l}9 \\
(\text { mean }=0.13 \\
S D=0.03)\end{array}$ & $<0.0001^{\mathrm{a}}$ \\
\hline 5. & Spinal cases & $\begin{array}{l}39 \\
(\text { mean }=0.65 \\
S D=0.05)\end{array}$ & $\begin{array}{l}17 \\
(\text { mean }=0.71, S D=0.1)\end{array}$ & $\begin{array}{l}1 \\
(\text { mean }=0.02, S D=0)\end{array}$ & $<0.0001^{\mathrm{a}}$ \\
\hline 6. & Mortality & $\begin{array}{l}2 \\
(\text { mean }=0.03, \\
S D=0.001)\end{array}$ & 0 & 0 & $<0.0001^{a}$ \\
\hline 7. & Discharges & $\begin{array}{l}120 \\
(\text { mean }=2, \\
S D=0.6)\end{array}$ & $\begin{array}{l}33 \\
(\text { mean }=1.37 \\
S D=0.5)\end{array}$ & $\begin{array}{l}20 \\
(\text { mean }=0.3 \\
S D=0.07)\end{array}$ & $<0.0001^{\mathrm{a}}$ \\
\hline
\end{tabular}

Abbreviations: COVID-19, coronavirus disease 2019; OPD, outpatient department; SD, standard deviation.

aStatistically significant $(p<0.05)$.

Table 3 Comparison of operated cases in emergency OT

\begin{tabular}{|l|l|l|l|}
\hline S. no & Cases & $\begin{array}{l}\text { Before pandemic } \\
\text { (January to February) }\end{array}$ & $\begin{array}{l}\text { During pandemic } \\
\text { (March to May) }\end{array}$ \\
\hline 1. & EDH & $31(33.7)$ & $20(27 \%)$ \\
\hline 2. & Acute SDH \pm contusion & $13(14.1 \%)$ & $13(17.6 \%)$ \\
\hline 3. & Chronic SDH & $8(8.7 \%)$ & $9(12.2 \%)$ \\
\hline 4. & Contusions & $22(23.9 \%)$ & $17(23 \%)$ \\
\hline 5. & Depressed fracture & $8(8.7 \%)$ & $6(8.1 \%)$ \\
\hline 6. & Hydrocephalus with raised ICT & $4(4.3 \%)$ & $3(4 \%)$ \\
\hline 7. & Brain tumors with midline shift & $1(1.1 \%)$ & $3(4 \%)$ \\
\hline 8. & Brain abscess & $1(1.1 \%)$ & $2(2.7 \%)$ \\
\hline 9. & Spinal trauma & $4(4.3 \%)$ & $1(1.3 \%)$ \\
\hline & Total number of cases & 92 & 74 \\
\hline
\end{tabular}

Abbreviations: EDH, extradural hematoma; ICT, intracranial tension; OT, operation theater; SDH, Sub dural hematoma.

\section{Discussion}

The clinical presentation of COVID-19 disease ranges from mild, moderate to severe disease. Severity of disease is heralded by severe pneumonia, acute respiratory distress syndrome, and septicemia progressing to septic shock. Coronavirus infection may also present as asymptomatic carrier state. Elderly and immunocompromised patients may show atypical symptoms. Usual presentations are fever, breathlessness, sore throat, dry cough, and generalized malaise and weakness. ${ }^{9}$ The progression of disease is attributed to cytokine storm (IL2 or interleukin-2, IL10, TNF $\alpha$ etc.). ${ }^{10}$ Studies have reported that intensive care unit (ICU) requirements in these symptomatic patients vary from 25 to $30 \%$.
Recovery starts from 2nd to 3rd week. Mortality associated with this disease varies from 2 to $3 \%{ }^{11}$

Any person presenting with the above mentioned symptoms with history of international/containment/hotspot zone travelling or having contacts with positive COVID-19 cases or persons having similar travelling history are suspected cases of COVID-19. However, asymptomatic and afebrile cases have been also reported. ${ }^{12}$ RT-PCR (reverse transcription polymerase chain reaction) for COVID-19 virus on secretions of nasopharyngeal and pharyngeal region, tracheal/endotracheal aspirates, and bronchoalveolar lavage sample is the investigation of choice for confirming COVID-19 infection..$^{12}$ The leucocyte count is normal or low (leukopenia) in severe disease. The C-reactive protein and 
Table 4 Psychological and physical impact on neurosurgery team (neurosurgeons, nursing and ground staff and patient and their attendants $(n=50)$

\begin{tabular}{|c|c|c|c|}
\hline S. no. & Psychological and physical impact on neurosurgical team & $\begin{array}{l}\text { Number of staff/surgeon } \\
(n=50)\end{array}$ & Percentage \\
\hline 1. & Depression & 5 & $10 \%$ \\
\hline 2. & Anxiety & 12 & $24 \%$ \\
\hline 3. & Fear of contacting the disease & 45 & $90 \%$ \\
\hline 4. & Fear of well-being of family and children & 45 & $90 \%$ \\
\hline 5. & Difficulty in transport & 45 & $90 \%$ \\
\hline 6. & Suffocation feeling in PPE kit & 20 & $40 \%$ \\
\hline 7. & Difficulty in breathing while using N95 mask & 15 & $30 \%$ \\
\hline 8. & Loss of self confidence & 8 & $16 \%$ \\
\hline 9. & Frustration & 6 & $12 \%$ \\
\hline 10. & Increase in aggression & 2 & $4 \%$ \\
\hline 11. & Lack of satisfaction with protective gears provided & 39 & $78 \%$ \\
\hline S. no. & $\begin{array}{l}\text { Psychological and physical impact on patient and their } \\
\text { attendants }\end{array}$ & $\begin{array}{l}\text { Number of persons } \\
(n=88)\end{array}$ & Percentage \\
\hline 1. & Fear of contacting disease & 88 & $100 \%$ \\
\hline 2. & Anxiety & 88 & $100 \%$ \\
\hline 3. & Depression & 15 & $17 \%$ \\
\hline 4. & Dissatisfaction with treatment provided & 27 & $30.7 \%$ \\
\hline 5. & Difficulty in getting food & 88 & $100 \%$ \\
\hline 6. & Difficulty in getting shelters near hospital & 72 & $81.8 \%$ \\
\hline 7. & Difficulty in follow-up after discharge & 63 & $71.6 \%$ \\
\hline 8. & $\begin{array}{l}\text { Declining further treatment due to poor condition of patient and fear } \\
\text { of contacting COVID-19 infection }\end{array}$ & 6 & $6.8 \%$ \\
\hline
\end{tabular}

Abbreviations: COVID-19, coronavirus disease 2019; PPE, personal protective equipment.

erythrocyte sedimentation rate are usually raised but procalcitonin levels are generally normal which may be raised if a bacterial co-infection is present. Higher levels of aminotransferase, prothrombin time, serum creatinine, D-dimer, ferritin, and lactate dehydrogenase are attributed to the severity of disease. ${ }^{12}$

The chest X-ray usually depicts findings of pulmonary infiltrates present bilaterally in late course of disease. The sensitivity and specificity of computed tomography scan (CT scan) of lungs are more with findings of bilateral pulmonary infiltrates and ground glass opacification. Subsegmental pulmonary consolidation may be present. Abnormal CT scans are utilized to diagnose coronavirus disease in suspected patients that have initially negative RT-PCR reports. ${ }^{13}$ Treatment is mainly symptomatic and supportive. ${ }^{14}$ As there is no proven or recommended treatment for coronavirus infection, main aim is to emphasize and practice prevention guidelines. There is substantial risk of transmission of COVID-19 infection to HCWs. ${ }^{15}$

In this study, there was significant reduction in neurotrauma admission rate, number of cranial and spinal injury cases, total number of emergency surgeries performed, number of conservatively managed cases, and mortality during lockdown phases when compared with prelockdown time. This can be attributed to restrictions on people for use of vehicle or other transport means and road/rail/air travel leading to a marked reduction in the incidence of accidents and neurotrauma. Moreover, limiting people to their homes by enacting law has also reduced neurotrauma cases. There was no significant difference between patterns of diagnosis of operated patients.

In this study, neurosurgical electives were the most affected due to pandemic as OPDs and elective surgery was completely shut down during the lockdown period as per government guidelines and later Telemedicine OPDs were started to help neurosurgical patients. This has worsened the prognosis of elective neurosurgical patients due to delay in elective surgery. This also had bad impact on neurosurgery resident training modules and practice. Though the use of online teaching modules as well as webinars had tried to fill neurosurgical teaching gap but most neurosurgical trainees were of the opinion that still practical aspects and operative part were neglected. Moreover, these were poor substitutes for conventional well-established training. In our study, only $23.1 \%$ of neurosurgeons agreed on change in practice based on what they learned from these activities and only $15.4 \%$ accepted improvement of skills based on virtual learning.

Health care workers are trained to work under stress. But COVID-19 pandemic is posing a significant effect on their mental health. Tan et $\mathrm{al}^{16}$ studied the impact of the COVID-19 
Table 5 Virtual classes and webinars as an alternative to actual neurosurgical resident training during COVID-19 pandemic

\begin{tabular}{|l|l|l|l|}
\hline S. no. & Characteristics & $\begin{array}{l}\text { Number of neurosurgery residents } \\
\text { and consultants } \\
(\boldsymbol{n}=13)\end{array}$ & Percentage \\
\hline 1. & Participation in neurosurgical virtual learning activities. & 11 & $84.6 \%$ \\
\hline 2. & Ready to pay fees to participate in webinars. & 6 & $46.1 \%$ \\
\hline 3. & $\begin{array}{l}\text { Increase in participation in neurosurgical virtual learning } \\
\text { activities in pandemic. }\end{array}$ & 11 & $84.6 \%$ \\
\hline 4. & $\begin{array}{l}\text { Participation in international/national organized virtual } \\
\text { learning activity. }\end{array}$ & 8 & $61.5 \%$ \\
\hline 5. & $\begin{array}{l}\text { Change in practice based on what they learned from } \\
\text { these activities. }\end{array}$ & 3 & $23.1 \%$ \\
\hline 6. & Improvement of skills based on virtual learning. & 2 & $15.4 \%$ \\
\hline 7. & Increased communication with professional colleagues. & 11 & $84.6 \%$ \\
\hline 8. & Future participation in virtual learning. & 11 & $84.6 \%$ \\
\hline 9. & $\begin{array}{l}\text { Alteration in neurosurgical training and education } \\
\text { strategies. }\end{array}$ & 4 & $30.8 \%$ \\
\hline
\end{tabular}

Abbreviation: COVID-19, coronavirus disease 2019.

pandemic on psychology of health care and found that prevalence of anxiety was $8.9 \%$, depression was $6.6 \%$, and clinical concern of PTSD was $7.7 \%$ in their study. In our study, most (90\%) of the neurosurgical health care providers had fear of contacting the COVID-19 disease and had fear of well-being of family and children and difficulty in transport. Anxiety was present in $24 \%$ and depression was present in $10 \%$ of the interviewed neurosurgery health care providers at our center. Therefore, psychological counseling to health care staff is as important as providing adequate personal protective gears for effective functioning.

At most of the centers, teams of neurosurgeons have been utilized as an intensive care specialist, patients are shifted in non-COVID wards, protocols for testing all patients ahead of neurosurgical procedures have been implemented, and hospitals have been rearranged to "hub-and-spoke" pattern to limit neurosurgery to selected centers. ${ }^{17,18}$ Recent studies have reported a decrease of more than $50 \%$ in their neurosurgical operative numbers worldwide during this pandemic. ${ }^{19}$ We found a drop of 76\% in neurosurgical emergency operated cases during pandemic.

Since personal protective equipment are in limited quantity, the safety of HCWs is a valid reason to operate only emergency procedures. ${ }^{20}$ The "Stanford protocol" whistled an alert during endonasal surgeries during the pandemic, quoting a transsphenoidal operation done in Wuhan, China where more than a dozen members of the operating team got infected due to coronavirus spread from nasopharyngeal and oropharyngeal regions. ${ }^{21}$ This has raised concerns regarding the use of endonasal procedures in neurosurgical procedures.

Impacts on patients and their attendants are also considerable. In our study, all of them were having fear of contacting the COVID-19 disease and were having difficulty in getting food and necessary transportation for patient. Proper rehabilitation and care of them is a challenge during this phase of COVID-19 pandemic.
Neurosurgeons should screen their remedial action in the light of any new requests put upon by their administrations. They should keep on auditing their own practices and results, recognizing and featuring any deficiencies emerging out of the current emergency. ${ }^{22}$

\section{Management Approach}

Based on our institutional protocol of management of emergency neurosurgical cases and delay in getting reports of COVID-19 samples by 24 to 48 hours due to heavy load of testing on the microbiology laboratory at our center, we formulated a management approach to handle the neurosurgical emergencies ( - Fig. 1).

Patient and their attendants coming to our center are scanned by thermal scanner for fever and are only allowed to enter after wearing masks. Patient entering the casualty is immediately screened for COVID-19 suspicion by dedicated team in casualty. Patients suspected of COVID-19 are shifted to COVID-designated neurosurgical ward. Patients in which emergency surgery is required are operated in COVID-designated neurosurgical operative theater (OT) and shifted back to COVID-designated ward and ICU. Sampling of suspected cases is done in COVID-designated wards for conservatively managed cases and during intubation in OT during surgery. If report comes positive, then patient is shifted to COVID-19 positive ward and ICU and the contacts and operating teams are quarantined and tested for COVID-19. If the report comes out to be negative, then the patients are shifted to special neurosurgical ward and ICU (-Fig. 1).

For nonsuspected neurosurgical patients, if the patient is managed conservatively, he/she is shifted to special neurosurgical ward and ICU. If emergency surgery is required, we use the same approach that is used for COVID-19 suspected patient (-Fig. 1). 


\section{Recommendations}

We practice and recommend the following precautions for safety of neurosurgeons and health care providers along with patients.

1. Mandatory thermal screening and mask for patient and their attendants before entering the hospital premises.

2. Consider universal COVID testing in all patients as a norm and work.

3. Unnecessary close contact with the patient should be avoided at all places including OPD, indoor, and OTs. Practice of frequent hand cleaning should be mandatory.

4. Maintain distance (1-2 m) and use a well-ventilated room as far as possible.

5. Questionnaire on COVID-19 should be strictly filled by patients and relatives.

6. In a COVID positive patients we must try to avoid nonemergency surgery if possible till they are negative.

7. The number of relatives with the patient should be restricted to only those who have been tested negative. However, due to limited testing facilities this is not feasible in many centers.

8. CT scan of chest to be done in all patients especially in those requiring emergency surgeries as findings by experienced radiologist are well correlated with RT-PCR.

\section{Operative Recommendation}

In neurosurgical operation innovation is the need of the hour. Neurosurgeons must adapt and invent ways to restrict aerosol generation and spread in OT. It is to be assumed that every OT is contaminated, and every patient is suspicious of being infected with COVID-19. We should take all necessary precautions and recommend safety guidelines. Restricting surgical procedures to only emergency procedures can help reducing transmission to HCWs. Also, preoperative RT-PCR for all symptomatic patients and high resolution computed tomography thorax for all preoperative patients should be done. If the critical condition of the patient does not allow waiting for RT-PCR report, then such emergency cases are presumed to be coronavirus positive. All staff attending OT should wear proper PPE as per the facility available. Minimum staff possible should be involved in performing surgery. OT cleaning staff should take droplet precautions. Portable UV sterilizers can be used to sanitize room and keys, wallet, N95 masks, etc. Within the OT room transparent fiberglass can be attached to the OT desk to shield the consultant from the patient. Surgeries without AC and in full PPE are very tiresome. Sufficient time should be allowed for OT room air exchange between cases (approximately 30 minutes). High-efficiency particulate air filtration should be used in buildings where windows cannot be opened. ${ }^{23}$

Negative pressure PPE suits with a motorized system to maintain the body temperature during long surgeries will be innovative. Intubation and extubation are done in a separate room from the OT, and central AC is kept switched off during intubation and extubation even in negative PCR patients.
Also, we do two CT screenings of lungs separated by at least 3 days before surgery even for PCR negative patients. Percutaneous tracheostomy should be promoted in patients requiring tracheostomy. When drill is used decrease the drill speed with use of semicircular closed umbrella like cover over area bring drilled to restrict aerosol spread. Elderly neurosurgeons with background comorbidities should avoid doing long duration surgeries in high-risk patients.

We have made a plastic shield which can be attached to microscope and will reduce the aerosol spread significantly. Surgical loupes cannot be routinely used. With visor, gloves touching the visor and becoming unsterile is a frequent happening. This should be avoided.

\section{OPD Recommendations}

In OPDs, patients should be assessed through video consultation and only if required, needed to be assessed further, at the discretion of the doctor, patient needs to be allowed into the examination chamber. The neurosurgeon examines the patient while wearing appropriate PPE. OPD chambers need transparent curtains separating the patients and doctors (minimum distance of $6 \mathrm{ft}$ ), reduce OPD registrations to 30\% in the initial period and restrict our surgeries to emergencies and semi electives. Do a second test for COVID-19 before discharge. There should be a common code, red warning facilities like common WhatsApp or Telegram group to inform everyone who might get infected unknowingly because of newly diagnosed COVID-19 patients in emergency or ward.

\section{Conclusion}

The COVID-19 pandemic is having a significant repercussion on health care facilities all over the world. For conserving resources elective surgical procedures should be limited. Only emergency and semi-emergency neurosurgical cases should be operated. All of the emergency surgical load is reduced in this lockdown period. This pandemic has also a negative impact on neurosurgical resident training program and psychology of both neurosurgical unit and patients. A strategic scheme for management approach should be created for sensible triaging of emergent neurosurgical cases keeping in mind the constraints, so neurosurgeons can keep on serving their patients without hurting them either neurologically through deferring medical or surgical procedure, or by superfluously presenting them to the coronavirus infection at the zenith of the COVID-19 disease surge.

\section{Funding \\ None.}

\section{Conflict of Interest}

None declared.

\section{References}

1 Wang C, Horby PW, Hayden FG, Gao GF. A novel coronavirus outbreak of global health concern. Lancet 2020;395(10223):470-473 
2 "Home | Ministry of Health and Family Welfare | GOI". Available at: https://www.mohfw.gov.in/. Accesssed April 11, 2020

3 The Lancet. India under COVID-19 lockdown. Lancet 2020;395(10233): 1315

4 Richman DD, Whitley RJ, Hayden FG, Clinical Virology. 4th ed. Washington: ASM Press; 2016

5 Rothe C, Schunk M, Sothmann P, et al. Transmission of 2019$\mathrm{nCoV}$ infection from an asymptomatic contact in Germany. N Engl J Med 2020;382(10):970-971

6 World Health Organization. Situation reports. Available at: https:// www.who.int/emergencies/diseases/novel-coronavirus-2019/situation-reports/. Accessed February 22, 2020

7 Kampf G, Todt D, Pfaender S, Steinmann E. Persistence of coronaviruses on inanimate surfaces and its inactivation with biocidal agents. J Hosp Infect 2020;104:246-251

8 Cheng ZJ, Shan J. novel coronavirus: where we are and what we know. Infection 2019;2020:1-9

9 National Institute of Health. COVID-19 Treatment GuidelinesOverview. Available at: https://www.covid19treatmentguidelines.nih.gov/introduction/. Accessed May 31, 2020

10 Chen N, Zhou M, Dong X, et al. Epidemiological and clinical characteristics of 99 cases of 2019 novel coronavirus pneumonia in Wuhan, China: a descriptive study. Lancet 2020;395(10223):507-513

11 Coronavirus Outbreak. Available at: https://www.worldometers.info/coronavirus/. Accessed February 23, 2020

12 Jin $\mathrm{YH}$, Cai L, Cheng ZS, et al; for the Zhongnan Hospital of Wuhan University Novel Coronavirus Management and Research Team, Evidence-Based Medicine Chapter of China International Exchange and Promotive Association for Medical and Health Care (CPAM). A rapid advice guideline for the diagnosis and treatment of 2019 novel coronavirus (2019-nCoV) infected pneumonia (standard version) Mil Med Res 2020;7(1):4

13 Huang P, Liu T, Huang L, et al. Use of chest CT in combination with negative RT-PCR assay for the 2019 novel coronavirus but high clinical suspicion. Radiology 2020;295(1):22-23

14 Chen Z-M, Fu J-F, Shu Q, et al. Diagnosis and treatment recommendations for pediatric respiratory infection caused by the 2019 novel coronavirus. World J Pediatr 2020;16(3):240-246
15 Chang D, Xu H, Rebaza A, Sharma L, Dela Cruz CS. Protecting health-care workers from subclinical coronavirus infection. Lancet Respir Med 2020;8(3):e13

16 Tan BYQ Chew NWS, Lee GKH, et al. Psychological impact of the COVID-19 pandemic on health care workers in Singapore. Ann Intern Med. 2020;173(4):317-320

17 Global Neuro Foundation. Global neuro-neurosurgical special report 2020-nCoV-neurosurgical practice during the pandemic learnings from the world's most affected countries; 2020. Available at: https://mailchi.mp/globalneuro/special_ report_2019_ncov. Accessed April 04, 2020

18 International Webinar Symposium: "Impact of COVid-19 on Neurosurgery"; 2020. Available at: https://www.youtube. com/watch?v=NIDWcrqkMIU. Accessed April 04, 2020

19 Jean WC, Ironside NT, Sack KD, Felbaum DR, Syed HR. The impact of COVID-19 on neurosurgeons and the strategy for triaging non-emergent operations: a global neurosurgery study. Acta Neurochir (Wien) 2020;162(6):1229-1240

20 Chang D, Xu H, Rebaza A, Sharma L, Dela Cruz CS. Protecting health-care workers from subclinical coronavirus infection. Lancet Respir Med 2020;8(3):e13

21 Patel, ZM, Fernandez-Miranda J, Hwang, PH, Nayak JV, Dodd, R, Sajjadi H, Jackler, R. Precautions for endoscopic transnasal skull base surgery during the COVID-19 pandemic. Available at: https://www.entcanada.org/wp-content/uploads/COVID-19_ endoSB_LettertoEditor_Neurosurgery.pdf; 2020. Accessed April 01, 2020

22 Tsermoulas G, Zisakis A, Flint G, Belli A. Challenges to neurosurgery during the coronavirus disease 2019 (COVID-19) pandemic. World Neurosurg 2020;139:519-525

23 European Centre for Disease Prevention and Control (EADC). Disinfection of environments in healthcare and non-healthcare settings potentially contaminated with SARS-CoV-2. Available at: https://www.ecdc.europa.eu/sites/default/files/ documents/Environmental-persistenceof-SARS_CoV_2-virusOptions-for-cleaning2020-03-26_0.pdf. Accessed May 31, 2020 